\title{
All Right Upper Abdominal Cysts are Not Hepatic Cyst
}

Loreno Enny ${ }^{1}$, Surabhi Garg ${ }^{2}$, Manjunath Shreyamsa ${ }^{3}$, Veladi Sasi Mouli ${ }^{4}$, Kul Ranjan Singh ${ }^{5}$, Pooja Ramakant ${ }^{6}$, Anand Mishra ${ }^{7}$

\author{
Abstract \\ Adrenal cysts are rare and uncommon disease with only around 600 cases reported so far. Cystic lesion in right hypochondria is usually of \\ hepatic in origin. The right adrenal cyst may sometimes be confused as the hepatic hydatid cyst. We herein report the case of a patient with \\ the adrenal pseudocyst who initially presented with features of the hepatic hydatid cyst. \\ Keywords: Adrenal cyst, Adrenalectomy, Hydatid cyst, Retroperitoneal. \\ World Journal of Endocrine Surgery (2020): 10.5005/jp-journals-10002-1297
}

\section{BACKGROUND}

Cystic lesions in right hypochondrium are usually of the hepatic origin. Rarely, cystic lesions from adjacent organs can mimic hepatic cysts. Adrenal cysts are rare and uncommon, with a reported incidence of $0.064-0.18 \%$ in autopsy studies. ${ }^{1}$ They account for $4-22 \%$ of all adrenal incidentaloma. ${ }^{2-4}$ Although more common in third to sixth decades, they can present in any age, with a female preponderance. ${ }^{5}$ We report an interesting case of a woman who initially presented with features of the hepatic hydatid cyst, further investigations suggesting an adrenal incidentaloma and postoperative histopathology revealing an adrenal pseudocyst.

\section{Case Description}

A 35-year-old lady who was under investigation for hepatic cystic lesion was referred to our department for further evaluation. She had initially presented with complaints of pain in the right upper abdomen for 5 months, which was insidious in onset, dull aching, nonradiating, and was relieved only on medication. There was no abdominal distension, vomiting, altered bowel, or bladder habits. She had no history suggestive of a functional adrenal mass. The patient had no comorbidities or significant past history. Her general examination and abdominal examination were essentially normal. Biochemical investigations showed a normal liver, renal, and adrenal functioning. ELISA for echinococcus was negative.

Ultrasonography of the abdomen, which was performed before the referral revealed an irregular cystic shadow, measuring $35 \times 33$ $\mathrm{mm}$ in the posterior segment of the right lobe of the liver with foci of calcification, was suggestive of the right hepatic hydatid cyst (Fig. 1).

Contrast-enhanced computed tomography (CECT) of the abdomen revealed a multiloculated cystic lesion measuring 31 $\times 32 \times 36 \mathrm{~mm}$ with multiple wall and septal calcification in the right adrenal region. The right adrenal gland was not visualized separately from the lesion. The image was suggestive of an adrenal cystic lesion (Fig. 2).

In view of patient's symptoms, surgical management was planned and retroperitoneoscopic adrenalectomy was performed. Intraoperatively, the lesion appeared multiloculated containing straw-colored fluid. It measured $4 \times 3 \mathrm{~cm}$ in size, with all borders free (Fig. 3). Both intraoperative and postoperative periods were uneventful and the patient was discharged on postoperative day 2 . The postoperative histopathology showed a cystic lesion with
${ }^{1-7}$ Department of Endocrine Surgery, King George's Medical University, Lucknow, Uttar Pradesh, India

Corresponding Author: Pooja Ramakant, Department of Endocrine Surgery, King George's Medical University, Lucknow, Uttar Pradesh, India, Phone: +91 9791507780, e-mail: poojaramakant@gmail.com

How to cite this article: Enny L, Garg S, Shreyamsa M, et al. All Right Upper Abdominal Cysts are Not Hepatic Cyst. World J Endoc Surg 2020;12(2):90-92.

Source of support: Nil

Conflict of interest: None

fibrocollagenous wall and no evident lining. Remnant of adrenal tissue is seen at the outer aspect. Histology was consistent with adrenal pseudocyst (Fig. 4).

\section{Discussion}

The adrenal cyst was first described by Viennese anatomist Greiselius in 1670 in a 45-year-old man who died due to rupture of an adrenal cyst weighing more than $4 \mathrm{~kg}{ }^{6}{ }^{6}$ The reported female to male ratio in literature is $3: 1 .^{5}$ They are usually unilateral and bilateral

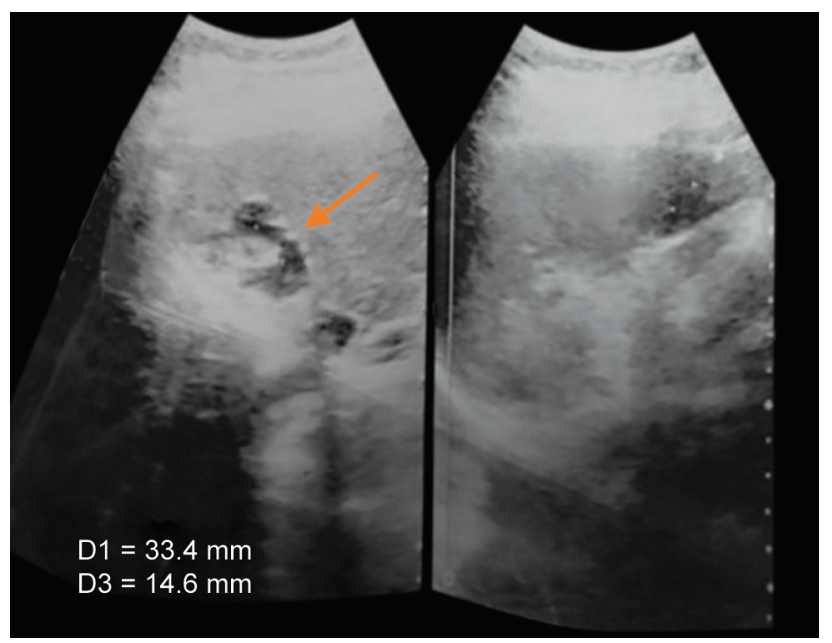

Fig. 1: Ultrasound image of right adrenal cyst confused as hepatic cyst

(0) The Author(s). 2020 Open Access This article is distributed under the terms of the Creative Commons Attribution 4.0 International License (https://creativecommons. org/licenses/by-nc/4.0/), which permits unrestricted use, distribution, and non-commercial reproduction in any medium, provided you give appropriate credit to the original author(s) and the source, provide a link to the Creative Commons license, and indicate if changes were made. The Creative Commons Public Domain Dedication waiver (http://creativecommons.org/publicdomain/zero/1.0/) applies to the data made available in this article, unless otherwise stated. 


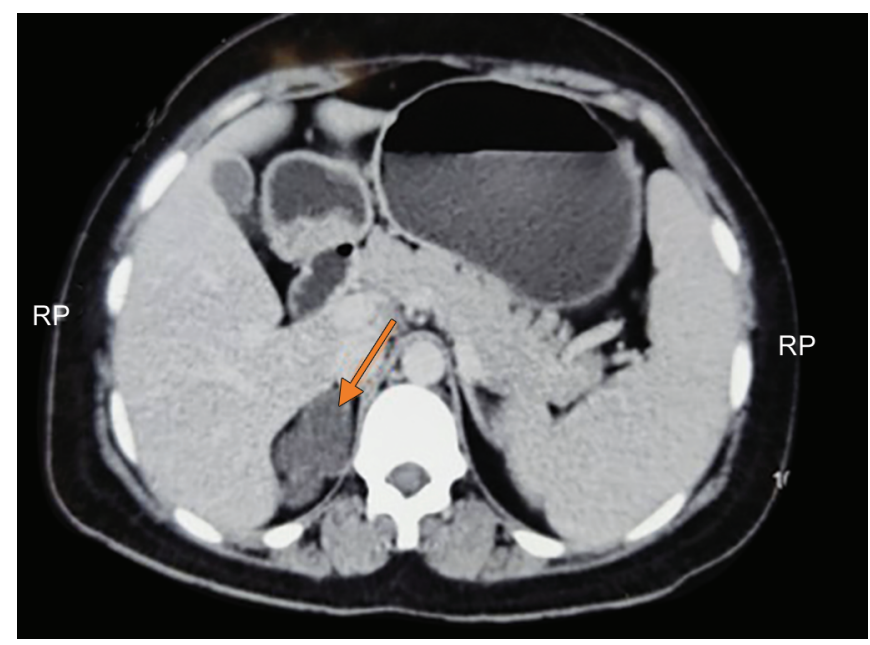

Fig. 2: CECT abdomen image confirming right adrenal cyst

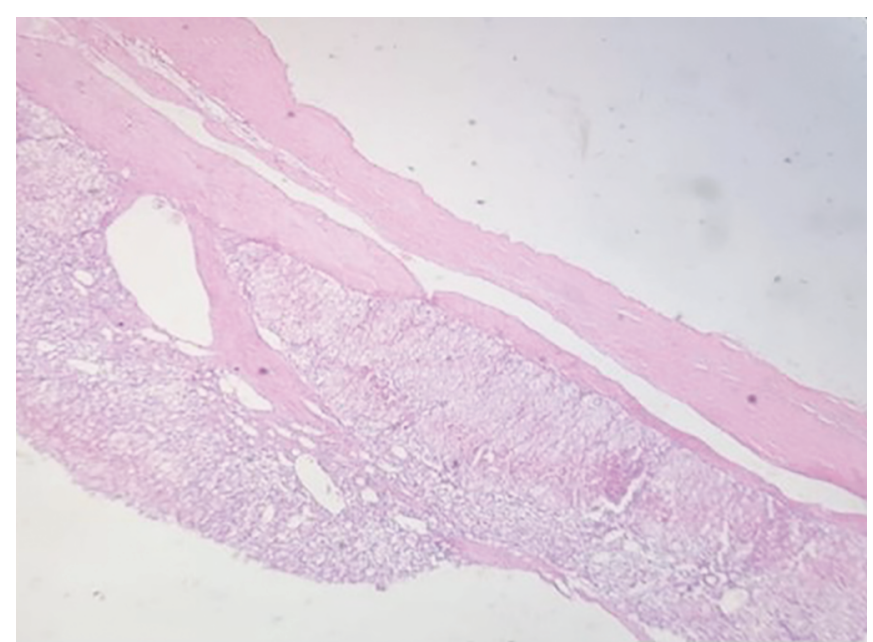

Fig. 4: Histopathology image of right adrenal pseudocyst

cysts and are seen in only about $8-15 \%$ of cases. ${ }^{1}$ Most of these cysts are benign in nature with reported incidence of malignancy in only $7 \%$ of cases. ${ }^{7}$ About $95 \%$ of these malignant lesions are metastases from other primary epithelial tumors (lung, kidney, colon, breast, pancreas, liver, and stomach), 3\% are pheochromocytoma, and remaining $2 \%$ are adrenocortical carcinomas., ${ }^{3,8}$ They are usually asymptomatic and are discovered incidentally. However, in about $39 \%$ of cases, they may present with large mass lesions and pain due to hemorrhage and cyst rupture. Rarely ( $9 \%$ of cases), adrenal cysts are associated with hypertension, probably due to compression of the adrenal artery or renal medulla. ${ }^{3}$

Terrier and Lecene in 1906 first classified adrenal cysts into hemorrhagic, endothelial, congenital retention, cystic adenomas, and parasitic types. ${ }^{9}$ Many other classifications were formulated eventually. In 1966, Foster classified the adrenal cyst into four types based on histological types and incidence: endothelial cyst (45\%), pseudocyst (39\%), epithelial cyst (9\%), and parasitic cyst (7\%). This remains the most accepted classification till date. ${ }^{6}$

\section{Pseudocyst}

Pseudocysts are most common among all adrenal cysts across different studies with an incidence of $39 \%$. ${ }^{6}$ They are usually large

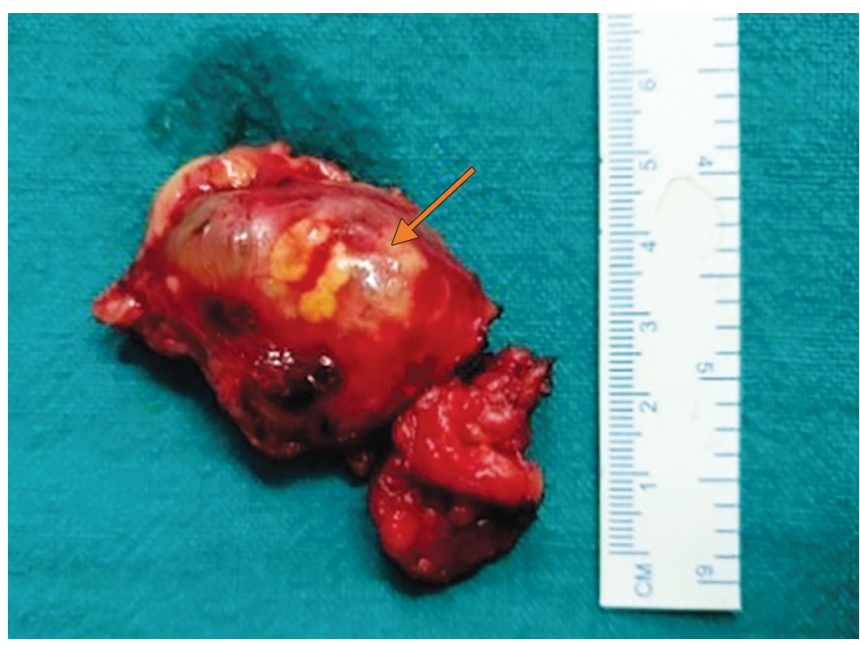

Fig. 3: Operative specimen of right adrenal cystic mass

and uniloculated with walls composed of the fibrous connective tissue devoid of any cellular lining. The walls are usually $1-5 \mathrm{~mm}$ thick, rarely reaching up to $3 \mathrm{~cm} .{ }^{6}$ Islands of the adrenal cortical tissue may be seen incorporated into the walls of the tumor in about $19 \%$ patients. ${ }^{10}$ They vary greatly in size, ranging from few millimeters to more than $50 \mathrm{~cm} .{ }^{11}$ Association of pseudocyst with adrenal neoplasm has been reported in about $18.7-44 \%$ of cases. ${ }^{10}$ Adrenal cysts can also be associated with variety of other conditions like polycystic renal disease, ${ }^{12}$ Beckwith-Wiedemann syndrome, ${ }^{13}$ Klippel-Trenaunay-Weber syndrome, ${ }^{14}$ abdominal aneurysm, and schwannomas. ${ }^{15,16}$ Rarely, they have been found in association with pregnancy. ${ }^{17}$ The etiopathogenesis includes hemorrhage within normal adrenal tissue or tumor, cystic degeneration of primary adrenal neoplasm, vascular neoplasm, and malformation. They may also result from other pathological conditions like toxemia of pregnancy, diabetes, uremia, toxemia of disseminated meningococcal infection, Waterhouse Friderichsen syndrome, acute crush injuries, and thrombosis of adrenal veins. ${ }^{6}$ Few researchers have reported an apparent vascular origin for pseudocysts, which is substantiated by the positive staining for endothelial markers in the walls of tumors. ${ }^{18}$

\section{Endothelial Cyst}

They are also known as simple cysts. They are the most common among adrenal cysts in autopsy series with incidence of $45 \%$, but account for only $2-24 \%$ of clinically symptomatic lesions. ${ }^{7}$ They are usually small in size, with an average size of less than $2 \mathrm{~cm}$. Bilateral lesions can be seen in about $8 \%$ of cases. ${ }^{1}$ The walls of these cysts are lined by a smooth flattened endothelial lining. ${ }^{7}$ Two subtypes of the endothelial cyst are described: lymph angiomatous type (94\%), which arise from ectasia of lymphatic vessels; and angiomatous type [6\%] arising from ectatic blood vessels..$^{5,7}$ Immunohistochemically, endothelial cysts express CD31 and factor VIII antigen. ${ }^{5,7}$

\section{Epithelial Cyst}

These are true cysts, with an incidence of $6-9 \% .^{6}$ They are mesothelial in origin and their walls are lined by smooth flattened epithelial lining. ${ }^{19}$ Different subtypes of epithelial cysts are reported, namely glandular or retention cyst, cystic adenomas, and embryonal cyst. ${ }^{10}$ Immunohistochemical staining of the walls demonstrates antibodies to keratin AE1/AE3. ${ }^{20}$ 


\section{Parasitic Cyst}

These are rare with an incidence of 7\%. ${ }^{6}$ Echinococcosis is the most common causative organism. They have thick walls with or without calcification. Eosinophilia can be noted in $20 \%$ of cases and are serologically positive in $90 \%$ of cases. ${ }^{7}$

As far as imaging is concerned, ultrasound has a reported sensitivity of $60-70 \%$ for detecting the adrenal cyst. ${ }^{21}$ The adrenal cyst on ultrasound reveals well-defined, round to oval anechoic structure showing posterior acoustic enhancement. The hyperechoic pattern may also be seen on ultrasound in case of hemorrhage in the cyst. Contrast-enhanced computed tomography of the abdomen is the gold standard imaging modality with a sensitivity of $85-100 \%$ and specificity of $95-100 \% .{ }^{21}$ On CECT, true cysts characteristically have fluid attenuation, usually lower than $20 \mathrm{HU}$, have smooth borders with thin nonenhancing walls. Lack of contrast enhancement on CT favors the diagnosis of the adrenal cyst. Calcification can be noted in around $15-70 \%$ of cases, which can be either rim or nodular calcification. MRI has a sensitivity of $100 \% .{ }^{21}$ On MRI, simple cyst appears hypointense on T1-weighted images and hyperintense on T2-weighted images without any soft tissue component or internal enhancement. In case of hemorrhage in adrenal pseudocysts, they appear hyperintense on both T1-and T2-weighted MRI images.

Optimum management of adrenal cysts still remains a controversy, owing to its low incidence. Surgical management, whether open or minimally invasive, depends on a surgeon's preference and expertise. Surgery is indicated in functional cysts, malignant or potentially malignant cysts, symptomatic cysts of any size, asymptomatic cysts of size more than $5 \mathrm{~cm}$, and those patients with uncertain follow-up.,22 Conservative management is apt in those with uncomplicated/asymptomatic cysts $<5 \mathrm{~cm} .{ }^{22} \mathrm{~A}$ minimum of 18 months of follow-up with repeat CT every 6 months is indicated. Aspiration of cyst can be considered as an alternative to surgery in case of surgically unfit patients. ${ }^{1,5,7}$ Marsupialization or decortication has also been tried as alternatives to surgery for large cysts especially those cysts that are adherent to multiple organs where excision may be difficult. ${ }^{5}$ Sclerotherapy using absolute alcohol has also been described but it is associated with high recurrence of $30-50 \%{ }^{1,5}$

\section{Conclusion}

In conclusion, cystic adrenal lesions are rare and uncommon disease and may present as diagnostic dilemma. Proper investigation including CT or MRI is essential for defining adrenal cystic lesion and differentiating from cystic lesion of adjacent organs. Surgery is the treatment of choice in symptomatic case and histopathological examination is essential for definitive diagnosis.

\section{REFERENCES}

1. Bellantone R, Ferrante A, Raffaelli M, et al. Adrenal cystic lesions: report of 12 surgically treated cases and review of the literature. J Endocrinol Invest 1998;21(2):109-114. DOI: 10.1007/BF03350324.
2. Dindo $D$, Demartines $M$, Clavien PA. Classification of surgical complications: a new proposal with evaluation in a cohort of 6336 patients and results of a survey. Ann Surg 2004;240(2):205-213. DOI: 10.1097/01.sla.0000133083.54934.ae.

3. Kuruba R, Gallagher SF. Current management of adrenal tumors. Curr Opin Oncol 2008;20(1):34-46. DOI: 10.1097/CCO.0b013e3282f301fd.

4. Turner DJ, Miskulin J. Management of adrenal lesions. Curr Opin Oncol 2009;21(1):34-40. DOI: 10.1097/CCO.0b013e32831d2aa9.

5. Tagge DU, Baron PL. Giant adrenal cyst: management and revieof the literature. Am Surg 1997;63:744-746.

6. Foster DG. Adrenal cysts. Review of literature and report of case. Arch Surg 1966;92(1):131-143. DOI: 10.1001/archsurg.1966.01320190133032.

7. Neri LM, Nance FC. Management of adrenal cysts. Am Surg 1999;65:151-163.

8. Stimac G, Katusic J, Sucic M, et al. A giant hemorrhagic adrenal pseudocyst: Case report. Med Princ Pract 2008;17(5):419-421. DOI: 10.1159/000141509.

9. Terrier F, Lecène P. Les grands kystes de la capsule surrénale. Rev de Chir Paris 1906;34:321.

10. Chien HP, Chang YS, Hsu PS, et al. Adrenal cystic lesions: a clinicopathological analysis of 25 cases with proposed histogenesis and review of the literature. Endocr Pathol 2008;19(4):274-281. DOI: 10.1007/s12022-008-9046-y.

11. Schmid $H$, Mussack $T$, Wörnle $M$, et al. Clinical management of large adrenal cystic lesions. Int Urol Nephrol 2005;37(4):767-771. DOI: 10.1007/s11255-005-4662-7.

12. Bastide C, Boyer L, Kjellouli N, et al. Bilateral adrenal cysts and hepatorenal polycystic disease. Presse Med 1997;26:711-712.

13. Ciftci AO, Salman AB, Tanyel FC, et al. Bilateral multiple adrenal pseudocysts associated with incomplete Beckwith-Wiedemann syndrome. J Pediatr Surg 1997;32(9):1388-1390. DOI: 10.1016/S00223468(97)90332-8.

14. Young SA, Shapiro B. Klippel-Trenaunay-weber syndrome with adrenal pseudocyst: characterization by blood pool and adrenocortical iodocholesterol scintigraphy. Clin Nucl Med 1998;23(8):528-531. DOI: 10.1097/00003072-199808000-00008.

15. Ardito G, Revelli L, Manni R, et al. Vascular cysts of the adrenals. Association with aneurysm of the abdominal aorta. Ann Ital Chir 1999;70:445-450.

16. Andreu J, Alegret $X$, érez $C$, et al. Cystic schwannoma mimicking adrenal tumor. Comput Med Imaging Graph 1988;12(3):183-185. DOI: 10.1016/0895-6111(88)90032-8.

17. Tait $D$, Williams J, Sandstad J, et al. Benign adrenal cyst presenting in a pregnant patient. Am J Perinatol 1997;14(08):461-464. DOI: 10.1055/s-2007-994180.

18. Torres C, Ro JY, BattMA, et al.Vascular adrenal cysts: a clinicopathologic and immunohistochemical study of six cases and a review of the literature. Mod Pathol 1997;10:530-536.

19. Suh J, Heimann A, Cohen H. True adrenal mesothelial cyst in a patient with flank pain and hematuria: a case report. Endocr Pathol 2008;19(3):203-205. DOI: 10.1007/s12022-008-9026-2.

20. Medeiros LJ, Weiss LM, Vickery Jr AL. Epithelial-lined [true] cyst of the adrenal gland: a case report. Hum Pathol 1989;20(5):491-492. DOI: 10.1016/0046-8177(89)90017-8.

21. Dogra VS, MacLennan GT, ed. Genitourinary Radiology: Male Genital Tract, Adrenal, and Retroperitoneum, vol. 211, London: SpringerVerlag; 2013.

22. Pradeep PV, Mishra AK, Aggarwal V, et al. Adrenal cysts: an institutional experience. World J Surg 2006;30(10):1817-1820. DOI: 10.1007/s00268-005-0307-3. 